\title{
Implementation of Linear and Nonlinear circuits using Operational Transconductance Amplifier
}

\author{
B.T.Krishna
}

\begin{abstract}
This paper describes implementation of CMOS based linear and non-linear analog circuitsusing operational trans conductance amplifier as the basic element. These circuits have their applications in communication and signal processing areas. In this work PSPICE is used for the simulation of various analog circuits. The corresponding results are presented.

Keywords:Operational Trans conductance Amplifier, Squaring Circuit, Multiplier, Full wave rectifier, Current mode.
\end{abstract}

\section{INTRODUCTION}

The implementation of some analog signal processing circuits using CMOS based OTA(Operational Transconductance Amplifier) has been discussed in this paper.Nowadays a huge amountof papers have been published on continuous-time analog CMOS [1] signal processing. Analog signals are represented as a set of continuous values whereas digital signals are represented as a series of discrete quantities.Analog values are typically represented as a voltage, electric current or electric charge around components in the electronic devices. Analog circuits use a continuous range of voltage as opposed to discrete levels as in digital circuits.

Recently, current mode circuits have become an attractive alternative for signal processing applications because of their inherent advantages over voltage mode circuits [2]. The advantages of current mode circuits are as follows,

- The main advantage of using current mode technique is dynamic range.

- $\quad$ For a fixed supply voltage, the dynamic range of a current mode circuit is much larger than that of a voltage mode circuit.

- Current mode circuits are much faster as compared to voltage mode circuits.

- In a current mode circuit, a change in current level is not necessarily accompanied by a change in the voltage level.

- Current mode circuits do not require specially processed capacitors or resistors; they are more compatible with digital CMOS technology making integration of mixed signal circuits more feasible.

Manuscript received on 03 April 2021 | Revised Manuscript received on 19 April 2021 | Manuscript Accepted on 15 September 2021 | Manuscript published on 30 September 2021. * Correspondence Author

B. T. Krishna*, Electronics and Communication Engineering Department, University College of Engineering Kakinada, Jawaharlal Nehru Technological University Kakinada, Kakinada, Andhra Pradesh, India. Email: tkbattula@gmail.com

(c) The Authors. Published by Lattice Science Publication (LSP). This is an open access article under the CC-BY-NC-ND license (http://creativecommons.org/licenses/by-nc-nd/4.0/)

Due to all the advantages of current mode analogue signal processing there has been an emergence of new analogue building blocks ranging from the current conveyor, OTA, OTRA and current feedback op-amps through to sampled data current circuits such as dynamic current mirrors and analogue neural networks.

The Paper is organized as follows. Details of the OTA are presented in Section II. Linear Applications are discussed in Section III. Non-Linear Applications are discussed in Section IV. Finally Conclusions are drawn in Section V.

\section{OPERATIONAL TRANSCONDUCTANCE AMPLIFIER}

An operational Transconductance amplifier (OTA) is a voltage controlled current source (VCCS) device [7]. The OTA is similar to a standard operational amplifier but output impedance is infinite in ideal OTA where it is zero in ideal Op-amp.In the ideal OTA, the output current is a linear function of the differential input voltage, and is given by:

IOUT $=g_{m}\left(V_{I N^{+}}-V_{I N^{-}}\right)$

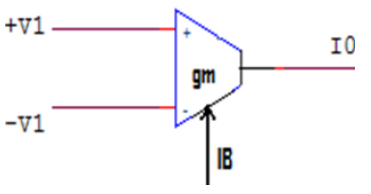

Figure 1.5 OTA Model

An ideal OTA is usually considered to have the following properties and they are considered to hold for all input voltages:

- Infinite input impedance

- Infinite output impedance (i.e. $\mathrm{R}_{\mathrm{out}}=\infty$ ).

- $g_{m}$ is variable and we cannot make $g_{m}$ infinite.

The OTA has been simulated using the CMOS structure of Figure 2 with DC supply voltage equal to $150 \mathrm{mV}$ and bias voltage equal to $\mathrm{V}_{\mathrm{DD}}=+5 \mathrm{~V}$ and $\mathrm{V}_{\mathrm{SS}}=-5 \mathrm{~V}$ and $\mathrm{I}_{\text {bias }}=50 \mu \mathrm{A}$. All MOS transistors are operated in saturation region and all of the bulks are connected to power supply voltage (bulks of PMOS are connected to $+5 \mathrm{~V}$, and bulks of NMOS are connected $-5 \mathrm{~V}$ ). The simulations are based on $.05 \mu \mathrm{m}$ CMOS technology. Fig. 2 shows the CMOS implementation of simple OTA. It uses only eight MOSFET transistors and one current source. Assume four MOS transistors operating in saturation region.

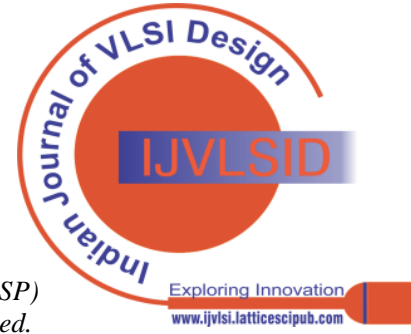




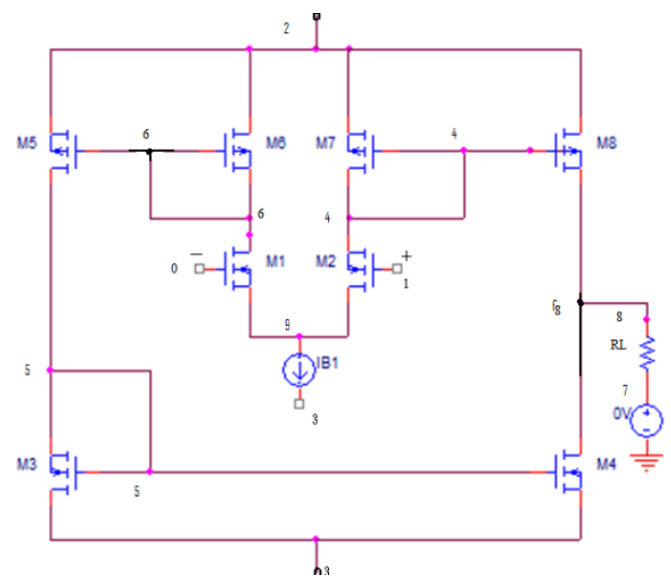

Fig 2: An OTA circuit using MOSFET

\section{LINEAR ANALOG SIGNAL PROCESSING APPLICATIONS}

A. Inverting Amplifier

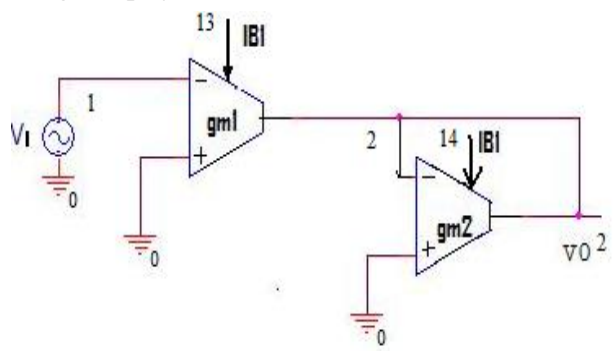

Fig.3.Inverting Amplifier

The voltage gain and output impedance are given by:

$I_{01}=-g_{m 1} V_{i n}(2)$

$I_{02}=-g_{m 2} V_{0}$

$I_{01}=-I_{02}$

On putting the value of Equations (2) and (3) in Equation (4), we get: $\frac{V_{i}}{V_{0}}=-\frac{g_{m 1}}{g_{m 2}}(5)$

B. Summer Circuit<smiles>O=CC1C2CC(O)C3CC1C(Br)(Br)C32</smiles>
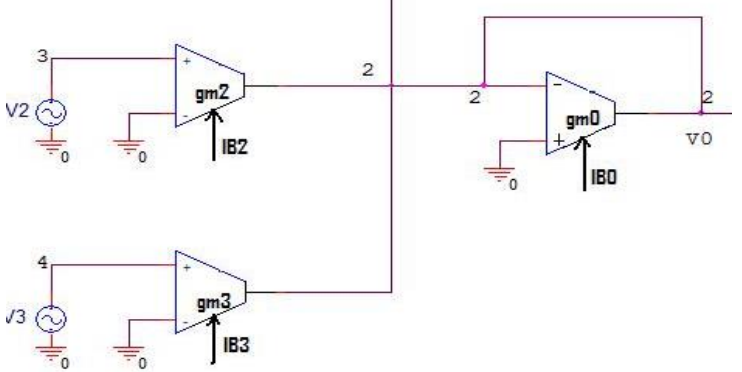

Fig.4.Summer Circuit

From the Circuit

$I_{01}=g_{m 1} V_{1}$

$I_{02}=g_{m 2} V_{2}$

$I_{03}=g_{m 3} V_{3}(8)$

On applying KCL as node 2, we get:

Retrieval Number:100.1/ijvlsid.B1201091221
$\mathrm{I}_{01}+\mathrm{I}_{02}+\mathrm{I}_{03}=\mathrm{g}_{\mathrm{m} 0} \mathrm{~V}_{0}(9)$

Putting the Equation (6), (7), and (8) in Equation (9)

$V_{0}=\left(\frac{g_{m 1}}{g_{m 0}} V_{1}+\frac{g_{m 2}}{g_{m 0}} V_{2}+\frac{g_{m 3}}{g_{m 0}} V_{3}\right)(10)$

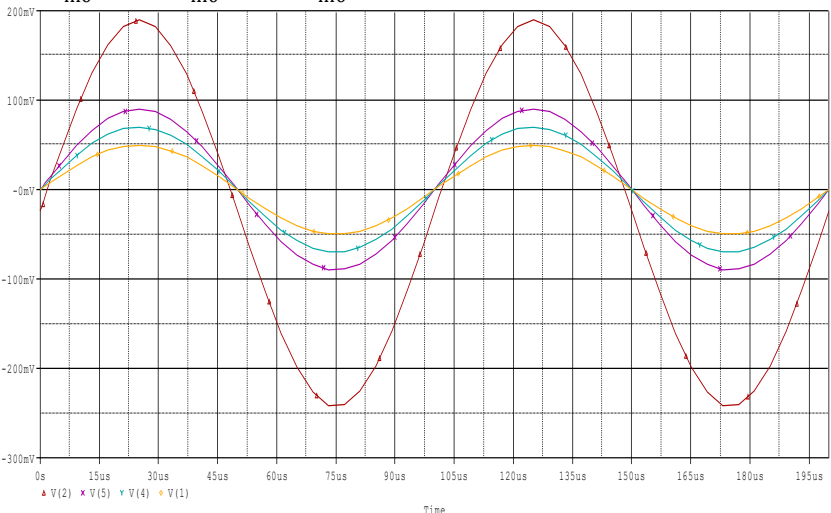

Fig.4.Simulation result of summer circuit.

C. First Order Filter

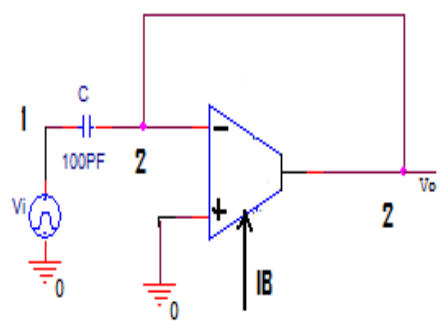

Fig.5.High Pass Filter Circuit.

$I_{0}=g_{m}\left(0-V_{0}\right)(11)$

$I_{0}=-g_{m} V_{0}$

$I_{0}=\frac{\left(V_{0}-V_{i}\right)}{1 / S C}$

NOW, Equation (13) can be written as:

$I_{0}=S C\left(V_{O}-V_{i}\right)(14)$

From Equation (12)

$-g_{m} V_{0}=S C\left(V_{O}-V_{i}\right)(15)$

$V_{i} . S C=V_{O}\left(S C+g_{m}\right)(16)$

${\frac{V_{0}}{V}}_{i}=\frac{S C}{S C+g_{m}}(17)$

So, the Equation (17) is the given transfer function of the High pass filter. 


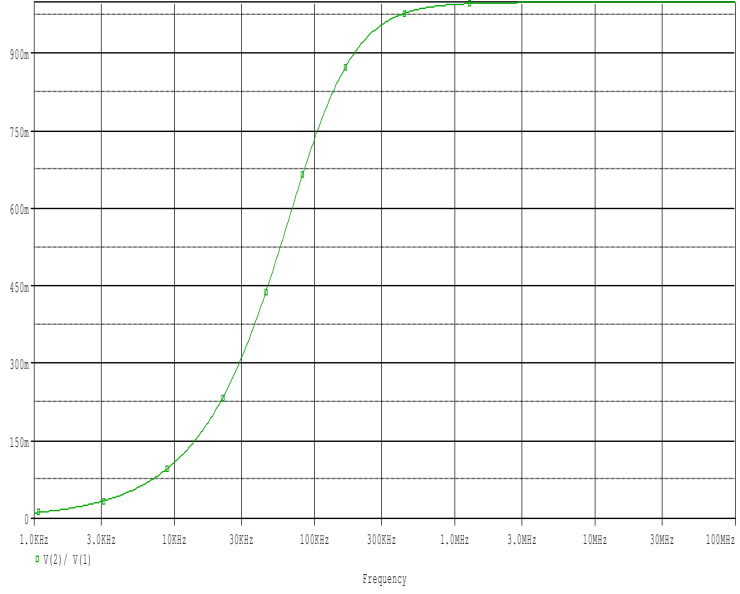

Fig.6.Simulation results of High pass Filter.

D. Low Pass Filter

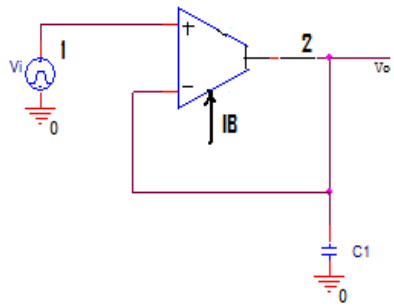

Fig.7.Lowpass Filter circuit.

$I_{0}=g_{m}\left(V_{i}-V_{0}\right)(18)$

$I_{0}=\frac{V_{0}}{1 / S C}$

On putting Equation (18) in Equation (19)

$V_{0 .} S C=g_{m}\left(V_{i}-V_{0}\right)(20)$

$V_{0 .}\left(g_{m}+S C\right)=g_{m} V_{i}(21)$

$\frac{V_{0}}{V_{i}}=\frac{g_{m}}{S C+g_{m}}(22)$

Hence, Equation (22) is the transfer function of the first order Low pass filter.

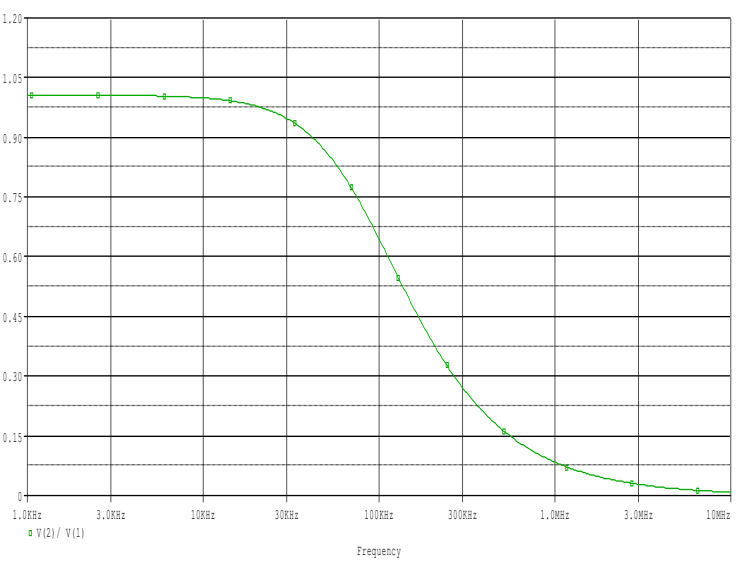

Fig.8.Simulation result of Lowpass circuit.

\section{NONLINEAR APPLICATIONS}

A. Integrator

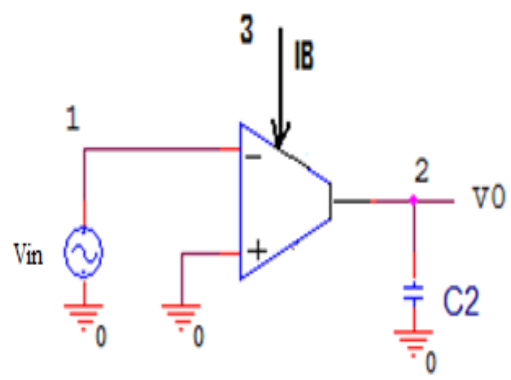

Fig.9.Integrator circuit.

Above Fig 9 is an integrator circuit using OTA, which have the advantage of varying output voltage by changing the bias current. So the output current is given by:

$\mathrm{I}_{0}=\mathrm{V}_{\mathrm{IN}} \cdot \mathrm{g}_{\mathrm{M}}(23)$

And output voltage in given by:

$\mathrm{V}_{0}=\frac{\mathrm{I}_{0}}{\mathrm{SC}}=\frac{\mathrm{V}_{\mathrm{IN} \cdot \mathrm{g}_{\mathrm{M}}}}{\mathrm{SC}}(24)$

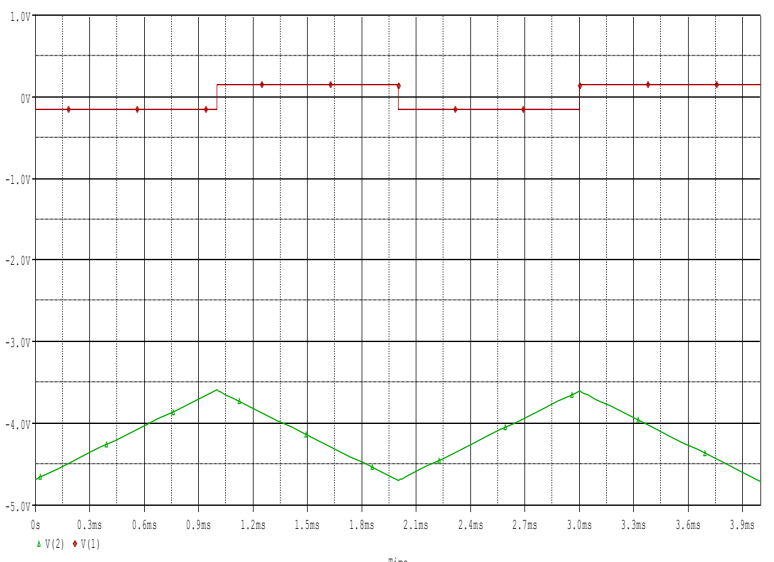

Fig.10.Simulation result of Integrator circuit.

B. Differentiator

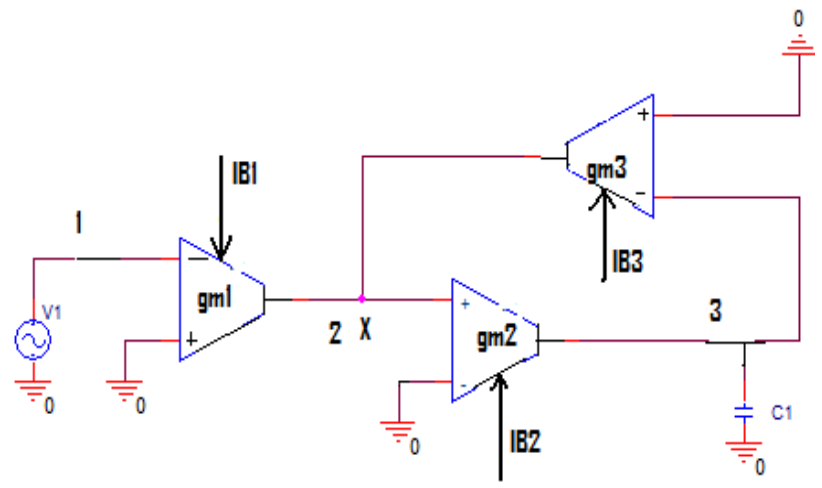

Fig.11.Differentiator circuit.

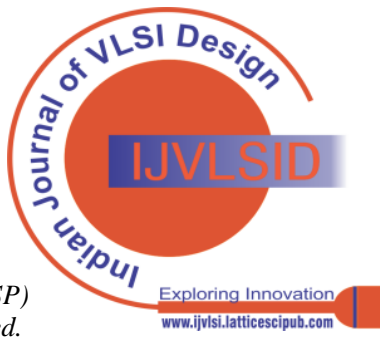


Now solving the above circuit, we get the following transfer function:

$$
I_{01}=g_{m 1}\left(0-V_{i}\right)
$$

$I_{01}=-g_{m 1} V_{i}$

$I_{02}=g_{m 2} V_{0}(26)$

$I_{03}=-g_{m 3} V_{c}(27)$

From Equation (26); voltage at node $\mathrm{X}$ is given by:

$V_{C}=\frac{1}{S C} g_{m 2} V_{0}(28)$

$V_{C}=\frac{1}{S C} I_{02}$

Applying KCL at node X, we get:

$I_{01}=-I_{03}(30)$

From above Equations,

$I_{03}=\frac{g_{m 2} g_{m 3} V_{0}}{S C}(31)$

Now, from Equation (29), (30) and (31),

$-\mathrm{g}_{\mathrm{m} 1} \mathrm{~V}_{\mathrm{i}}=\frac{\mathrm{g}_{\mathrm{m} 2} \mathrm{~g}_{\mathrm{m} 3} \mathrm{~V}_{0}}{\mathrm{SC}}(32)$

$\frac{V_{0}}{V_{i}}=-\frac{S C}{g_{m}}$

If, $g_{\mathrm{m} 1}=\mathrm{g}_{\mathrm{m} 2}=\mathrm{g}_{\mathrm{m} 3}=\mathrm{g}_{\mathrm{m}}$, then we get the following relation;

${\frac{V_{0}}{V_{i}}}_{i}=-S C \cdot R(34)$

Where; $g_{m}=1 / R$.So, Equation (34) is the transfer function of the ideal differential amplifier.

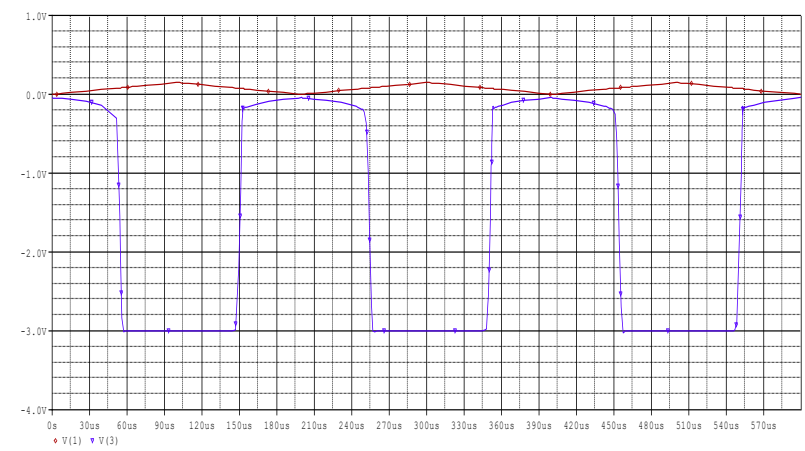

Fig.4.Simulation result of differentiator circuit.

\section{CONCLUSION}

In this project work simulation of analog circuits is presented by using CMOS-OTA. It is observed that OTA based circuits have good response on higher frequency.This work concentrates on the development of linear and non-linear analog integrated circuits for real time processing of data designed in 0.5-micron and 0.18 micron technology. The circuits are simulated using the PSPICE Tools. Simulation results show that the various characteristics are in good agreement with the theory.

\section{REFERENCES}

1. Toumazou C, Lidjey FJ, Haigh D. Analog IC design: the current-mode approach. Peter Peregrinus, UK: Exeter; 1990.

2. Khaled n. Salama, Ahmed m. Soliman,CMOS operational transresistance amplifier for analog signal processing - 1999 [CrossRef]
3. J.J. Chen, H.W. Tsao, and C. Chen, "Operational transresistance amplifier using CMOS technology." Electronics Letters, vol. 28, no. 22 pp. 2087-2088, 1992. [CrossRef]

4. Khan IA, Ahmed MT, Minhaj N ,A simple realization scheme for OTA-c universal biquadratic filter. International Journal of Electronics 1992 419-29. [CrossRef]

5. Haitham K. Ali, MA Jihan S. Abdaljabar, "Analysis and Simulation of Active Filters Using Operational Transconductance Amplifier (OTA)", European Scientific Journal, May 2017 edition Vol.13, No.15 [CrossRef]

6. Application of the Operational Transconductance Amplifier (OTA) to Voltage-Controlled Amplifiers and Active Filters: Department of IET Morehead State University Morehead

7. Sedra, A.S., and Smith, K.C., Microelectronic Circuits, 3rd Ed.,Chapter 6. Saunders College Publishing, N.Y., 1991.

\section{AUTHORS PROFILE}

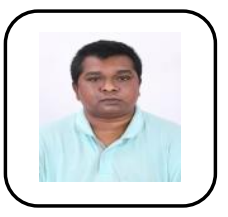

B.T.Krishna, completed his Ph.D. degree at the College of Engineering, Andhra University, Visakhapatnam, India. He is currently working at the Department of ECE, Jawaharlal Nehru Technological University Kakinada (JNTUK), Kakinada, India. His research areas of interest are signal processing, and analog VLSI.

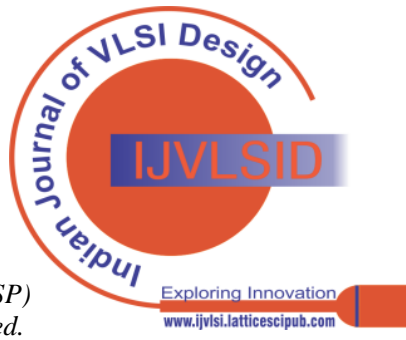

